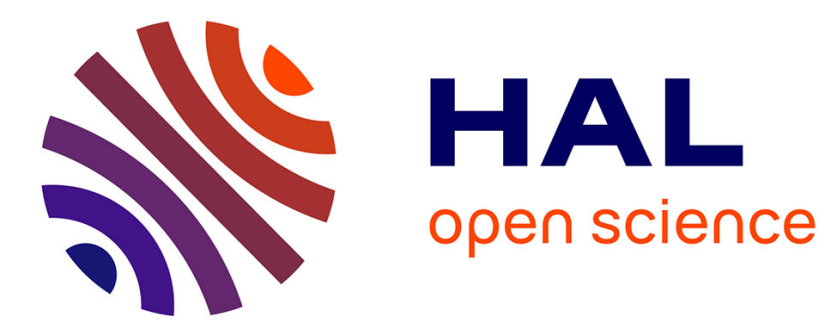

\title{
Atmospheric Photosensitization: A New Pathway for Sulfate Formation
}

Xinke Wang, Rachel Gemayel, Nathalie Hayeck, Sébastien Perrier, Nicolas Charbonnel, Caihong Xu, Hui Chen, Chao Zhu, Liwu Zhang, Lin Wang, et al.

\section{> To cite this version:}

Xinke Wang, Rachel Gemayel, Nathalie Hayeck, Sébastien Perrier, Nicolas Charbonnel, et al.. Atmospheric Photosensitization: A New Pathway for Sulfate Formation. Environmental Science and Technology, 2020, 54 (6), pp.3114-3120. 10.1021/acs.est.9b06347 . hal-02566392

\section{HAL Id: hal-02566392 https://hal.science/hal-02566392}

Submitted on 18 Nov 2020

HAL is a multi-disciplinary open access archive for the deposit and dissemination of scientific research documents, whether they are published or not. The documents may come from teaching and research institutions in France or abroad, or from public or private research centers.
L'archive ouverte pluridisciplinaire HAL, est destinée au dépôt et à la diffusion de documents scientifiques de niveau recherche, publiés ou non, émanant des établissements d'enseignement et de recherche français ou étrangers, des laboratoires publics ou privés. 


\section{Atmospheric photosensitization: a new pathway for sulfate formation}

Xinke Wang ${ }^{\dagger}$, Rachel Gemayel ${ }^{\dagger}$, Nathalie Hayeck ${ }^{\dagger}$, Sebastien Perrier ${ }^{\dagger}$, Nicolas Charbonnel ${ }^{\dagger}$, Caihong $\mathrm{Xu}^{\ddagger}$, Hui Chen ${ }^{\ddagger}$, Chao Zhu ${ }^{\ddagger}$, Liwu Zhang ${ }^{\ddagger}$, Lin Wang ${ }^{\ddagger}$, Sergey A. Nizkorodov ${ }^{\S}$, Xinming Wang"l, Zhe Wang ${ }^{\perp}$, Tao Wang ${ }^{\perp}$, Abdelwahid Mellouki ${ }^{\#}$, Matthieu Riva ${ }^{\dagger}$, Jianmin $^{\prime}$ Chen $^{\ddagger, \mathbb{q}, *}$, Christian George ${ }^{\dagger+*}$

†Univ Lyon, Université Claude Bernard Lyon 1, CNRS, IRCELYON, F-69626, Villeurbanne, France. ‡Shanghai Key Laboratory of Atmospheric Particle Pollution and Prevention (LAP3), Department of Environmental Science \& Engineering, Institute of Atmospheric Sciences, Fudan University, Shanghai 200438, China.

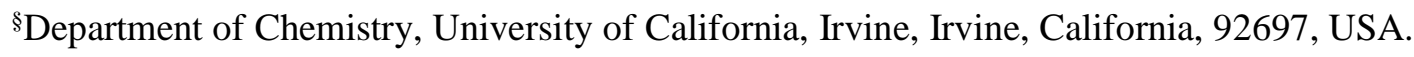

"State Key Laboratory of Organic Geochemistry and Guangdong province Key Laboratory of Environmental Protection and Resources Utilization, Guangzhou Institute of Geochemistry, Chinese Academy of Sciences, Guangzhou 510640, China

${ }^{\perp}$ Department of Civil and Environmental Engineering, The Hong Kong Polytechnic University, Hong Kong, China.

\#Institut de Combustion, Aérothermique, Réactivité et Environnement (ICARE), CNRS/OSUC, 45071

Orléans Cedex 2, France

"Institute of Eco-Chongming, 3663 Zhongshan Road, Shanghai 200062, China

*To whom correspondence should be addressed. Email: christian.george@ircelyon.univ-lyon1.fr, Email : jmchen@fudan.edu.cn 


\section{Abstract}

Northern China is regularly subjected to intense wintertime "haze events", with high levels of fine particles that threaten millions of inhabitants. While sulfate is a known major component of these fine haze particles, its formation remains unclear especially under highly polluted conditions, with state-of-the-art air quality models unable to reproduce or predict field observations. These haze conditions are generally characterized by simultaneous high emissions of $\mathrm{SO}_{2}$ and photosensitizing materials. In this study, we find that the excited triplet states of photosensitizers could induce a direct photosensitized oxidation of hydrated $\mathrm{SO}_{2}$ and bisulfite into sulfate $\mathrm{S}(\mathrm{VI})$ through energy transfer, electron transfer or hydrogen atom abstraction. This photosensitized pathway appears to be a new and ubiquitous chemical route for atmospheric sulfate production. Comparing to other aqueous-phase sulfate formation pathways with ozone, hydrogen peroxide, nitrogen dioxide, or transition metal ions, the results also show that this photosensitized oxidation of S(IV) could make an important contribution to aerosol sulfate formation in Asian countries, particularly in China.

\section{Introduction}

Fine particulate matter, a complex cocktail of inorganic and organic species, has a central role during persistent haze events in the North China Plain. While sulfate $\left(\mathrm{SO}_{4}{ }^{2-}\right)$ is ubiquitous and a key component, its production from $\mathrm{SO}_{2}$ is still uncertain. While gaseous $\mathrm{SO}_{2}$ can be oxidized through its reaction with $\mathrm{OH}$ radicals, it also undergoes significant multiphase processing through reactions involving a variety of dissolved oxidants such as ozone $\left(\mathrm{O}_{3}\right)$, hydrogen peroxide $\left(\mathrm{H}_{2} \mathrm{O}_{2}\right)$, and transition metal ions (TMIs) ${ }^{1-3}$. However, the detailed chemical mechanism under heavily polluted conditions remains uncertain. Current atmospheric observations highlighting high sulfate production during severe haze events ${ }^{4}$ cannot be reproduced by atmospheric models ${ }^{5}$. To close this 
gap, new chemical pathways have been suggested involving an interfacial $\mathrm{SO}_{2}$ oxidation on acidic microdroplets ${ }^{6}, \mathrm{SO}_{2}$ triplet state chemistry ${ }^{7-9}$ or oxidation at higher $\mathrm{pH}$ via a reaction with $\mathrm{NO}_{2}{ }^{10}$,

11. In sum, despite intense research efforts, important missing processes hamper our abilities to clearly elucidate the formation of one of the most important components of haze particles.

Photosensitized chemistry has been recently discussed as triggering novel chemistry in tropospheric particles ${ }^{12}$, but its role for S(IV) oxidation under polluted conditions has not been explored. A photosensitizing molecule will absorb solar radiation and create an excited (triplet) state $\mathrm{T}^{*}$ from which various chemical pathways can be initiated that would otherwise not take place at ground state ${ }^{13}$. Biomass burning for residential heating, typical for China during haze events, are in fact a likely source of compounds bearing functional groups capable of photosensitized oxidation as observed in HULIS (Humic Like Substances) ${ }^{14}$. We therefore investigated whether photosensitized oxidation of $\mathrm{SO}_{2}$ may occur under atmospheric conditions, as an attempt to close some gaps in our knowledge of sulfate formation under polluted conditions.

\section{Materials and Methods}

All experiments were conducted at room temperature in the range of 295-300 K.

Chemicals. All chemicals were used as purchased: acetophenone (Sigma Aldrich, 98\%), flavone (Sigma Aldrich, $\geq 99.0 \%$ ), xanthone (Sigma Aldrich, 97\%), 4- (benzoyl)benzoic acid (4BBA, Sigma Aldrich, 99\%), sodium sulfite (Sigma Aldrich, $\geq 98 \%$ ), sulfuric acid (Sigma Aldrich, 95-97\%), humic acid (HA, Sigma Aldrich, technical grade), humic acid salt (HAS, Sigma Aldrich, technical grade). In addition, all solutions were freshly prepared using ultrapure water (Elga Purelab Classic, 18.2 M $\Omega \mathrm{cm}$ ). In order to promote dissolution, 4-BBA solutions were stirred in an ultrasonic bath for 10 min, and the solutions of xanthone and flavone were agitated for 2 hour 
in the dark, both at ambient temperature. For the chromatographic analysis, acetonitrile, water and formic acid were all three of Optima ${ }^{\circledR}$ LC/MS grade, provided by Fisher Scientific. O- $(2,3,4,5,6$ pentafluorophenyl) methylhydroxyl amine hydrochloride (PFBHA, $\geq 99.0 \%$ ) was also purchased from Fluka. In addition, $\mathrm{SO}_{2}\left(10 \mathrm{ppm}\right.$, mixing with pure $\mathrm{N}_{2}$, Linde, France) and $\mathrm{N}_{2}(99.999 \%)$ were used in this study.

PM2.5 samples collection and extraction. 24-hour ambient aerosol samples ( $\mathrm{PM}_{2.5}$ masses in the range of 27-46 mg) were collected onto $90 \mathrm{~mm}$ prebaked quartz-fiber filters (Whatman Company, UK) during 10 to 14 December 2018, using a mid-volume sampler (TH-150A, Wuhan Tianhong, China) operating at $100 \mathrm{~L} \mathrm{~min}^{-1}$. The sampling site was located in rural Wangdu $\left(38^{\circ} 42^{\prime}\right.$ N, $115^{\circ} 08^{\prime}$ E), Baoding, Hebei Province, surrounded by grasslands and farms, but easily influenced by industrial and urban plumes from megacities such as Beijing, Tianjin, and Shijiazhuang. After sampling, filters were stored at $-20^{\circ} \mathrm{C}$ in a freezer before further analysis.

Each quartz filter was extracted with three subsequent $15 \mathrm{~mL}$ extractions of ultrapure water and agitated for $25 \mathrm{~min}$ on an orbital shaker set at $1000 \mathrm{rpm}$. After filtering through a $0.2 \mu \mathrm{m}$ polytetrafluoroethylene membrane (13 mm, Pall Corporation, USA) using a glass syringe, the combined ambient aerosol extracts (AA as abbreviation) were used to conduct the photochemical experiments described below. In addition, in order to characterize chromophores and carbonylcontaining compounds, these extracts were analyzed by using a UPLC/DAD/(+/-)HESI-HRMS platform, which is the combination of ultra-high performance liquid chromatography (UPLC, Dionex 3000, Thermo Scientific, USA), a diode array detector (DAD), and an Orbitrap high resolution mass spectrometer (HRMS, Q Exactive, Thermo Scientific, Bremen, Germany) using heated electrospray ionization (HESI). More Information about chemical analysis of filter samples were illustrated in the Supporting Information. 
Quartz cell experiments. A $14 \mathrm{~mL}$ cylindrical quartz cell (5 cm length and $2 \mathrm{~cm}$ diameter) mounted $13 \mathrm{~cm}$ away along its axis of a Xenon lamp (150 W; LOT-QuantumDesign, France) used to perform the experiments. A quartz water filter of $5 \mathrm{~cm}$ length and a Pyrex filter were mounted in front of the lamp to remove infra-red irradiation and short wavelengths $(\lambda<290 \mathrm{~nm})$. The spectral characteristics of this system can be found in Figs. 5 of Ciuraru et al. ${ }^{15}$. In order to maximize the surface to volume ratio $\left(1.4 \mathrm{~cm}^{2} \mathrm{~cm}^{-3}\right)$, the cell was half-filled with $7 \mathrm{~mL}$ of pure water, $75 \mu \mathrm{M}$ 4-BBA, $70 \mathrm{mg} \mathrm{L}^{-1} \mathrm{HA}, 70 \mathrm{mg} \mathrm{L}^{-1} \mathrm{HAS}$, or AA (diluted by adding $1 \mathrm{~mL}$ ultrapure water or water acidified with sulfuric acid $\left(\mathrm{H}_{2} \mathrm{SO}_{4}\right)$ to a desired $\mathrm{pH}$, see below), respectively. An incoming diluted $\mathrm{SO}_{2}$ gas flow (around $83 \mathrm{ppb}$ after diluting by pure air) with a flowrate of 300 $\mathrm{mL} \mathrm{min}^{-1}$ was injected through the cell and further diluted by adding $200 \mathrm{~mL} \mathrm{~min}{ }^{-1} \mathrm{~N}_{2}$, then analyzed afterwards by a $\mathrm{SO}_{2}$ analyzer (Thermo, 43i). At the beginning of all experiments, higher concentrations of $\mathrm{SO}_{2}$ were injected into the reactor in order to more rapidly reach the $\mathrm{SO}_{2}$ gas/liquid equilibrium. In other words, these solutions were pre-conditioned with flowing gaseous $\mathrm{SO}_{2}$ to establish Henry's law and acid-base equilibria producing hydrated $\mathrm{SO}_{2}, \mathrm{HSO}_{3}{ }^{-}$and $\mathrm{SO}_{3}{ }^{2-}$, according to Eqs. 1-3:

$$
\mathrm{SO}_{2(\mathrm{~g})} \rightleftharpoons \mathrm{SO}_{2}(\mathrm{aq})
$$

$$
\mathrm{SO}_{2}(\mathrm{aq})+\mathrm{H}_{2} \mathrm{O} \rightleftharpoons \mathrm{HSO}_{3}{ }^{-}+\mathrm{H}^{+}(\mathrm{pKa} \sim 1.88 \text { at } 298 \mathrm{~K})
$$

$$
\mathrm{HSO}_{3}{ }^{-} \rightleftharpoons \mathrm{SO}_{3}{ }^{2-}+\mathrm{H}^{+}(\mathrm{pKa} \sim 7.22 \text { at } 298 \mathrm{~K})
$$

09 Sulfate concentrations in the liquid phase were measured using ion chromatography (IC, 10 Metrohm, 881 Compact IC Pro - Anion, Switzerland). $\mathrm{H}_{2} \mathrm{SO}_{4}$ was added to adjust the pH of $\mathrm{HA}$, 11 HAS, and AA1 solutions, which were 4.0, 4.6, and 4.6, respectively. The pH of 4-BBA and AA2 
solutions were 4.4 and 6.2, respectively, without adding $\mathrm{H}_{2} \mathrm{SO}_{4}$. Due to the high pH of AA2 solution, $\mathrm{SO}_{2}$ concentrations in the gas/liquid phase did not reach the equilibrium even after injecting higher concentrations of $\mathrm{SO}_{2}$ for over an hour. In addition, the 4-BBA solutions were degassed by bubbling pure $\mathrm{N}_{2}$ around $30 \mathrm{~min}$ at a flowrate of $25 \mathrm{~mL} \mathrm{~min}{ }^{-1}$, which was also used to conduct the same experiment. Meanwhile, the incoming $\mathrm{N}_{2}$ instead of pure air went through the quartz cell continuously. In all these experiments, the solutions were irradiated 50 min, except for pure water (irradiated $40 \mathrm{~min}$ ).

Aerosol flow tube experiments. Experiments were carried out at atmospheric pressure by using a horizontal jacketed aerosol flow tube (AFT, $6 \mathrm{~cm}$ internal diameter and $180 \mathrm{~cm}$ length) made of Pyrex. The air flowing through the reactor was kept at constant temperature of $293 \pm 1 \mathrm{~K}$ by means of a circulating water bath. There are 5 UV-lamps (Cleo, Philips, Netherlands) surrounding the flow tube with a continuous emission spectrum over 300-420 nm and a total irradiance from 0.75 $\times 10^{15}$ to $3.77 \times 10^{15}$ photon $\mathrm{cm}^{-2} \mathrm{~s}^{-1}$, which has been described elsewhere ${ }^{16} .4$-BBA aerosols were generated from an aqueous solution $(0.15 \mathrm{mM})$ by means of a constant-output atomizer (TSI Model 3076). A portion of the aerosol flow $\left(\sim 0.33 \mathrm{~L} \mathrm{~min}^{-1}\right)$ was dried using a Silica gel diffusion dryer and monodispersed particle diameters of 70 or $80 \mathrm{~nm}$ were selected for analysis with the differential mobility analyzer (DMA, TSI model 3081, impactor size $0.0508 \mathrm{~cm}$ ), then mixed with $\mathrm{SO}_{2}$ gas (22 $\mathrm{mL} \mathrm{min}^{-1}$, $630 \mathrm{ppb}$ after mixing) and injected into the AFT. The relative humidity measured at the outlet of the AFT was in the range of $25-27 \%$. Seed particle concentration was approximately 800 particles $\mathrm{cm}^{-3}$ and the residence time was $\sim 15 \mathrm{~min}$. A compact time of flight aerosol mass spectrometer (AMS, Aerodyne Inc.) was used to sample and analyze aerosols upon exiting the AFT. The obtained mass spectra were analyzed by using the AMS analysis software Squirrel version 1.60P and Pika version 1.20P. Water particles instead of 4-BBA particles were 
used as control experiments. During the control experiments, the Silica gel diffusion dryer was moved from its normal position in front of the AFT to a position downstream from the AFT and in the front of the AMS to allow water particles to enter the AFT without evaporation. In addition, all water particles were injected into the AFT without being size selected.

Pulsed laser excitation experiments. The transient absorption spectra of the excited acetophenone, flavone, xanthone, 4-BBA and HULIS (extracted from the ambient aerosols) were measured using a pump-probe system described earlier ${ }^{17}$, and the experimental setup was shown in Fig. S1. The third harmonic (266 nm, pulse width 7 ns) of a Nd:YAG laser (Surelite II 10, Continuum) was used as an excitation source, operating in a single-shot mode. During these experiments, the laser pulse energy was limited at $10 \mathrm{~mJ}$ per pulse $\left(\sim 6 \mathrm{~mJ} \mathrm{~cm}^{-2}\right)$ in order to reduce the undesirable photolysis of the photosensitizer and avoid possible interferences from products. To avoid any interference or electron transfer with oxygen, the photosensitizer solutions were deoxygenated by bubbling argon through them for at least 20 min. The setup and principle of the pulsed laser system were described in detail in the Supporting Information.

For the kinetic measurements, the probe wavelengths for the transient absorption decay of the acetophenone, flavone, xanthone, and 4-BBA triplet state were 360, 350, 590, and $560 \mathrm{~nm}$, respectively, which were around the corresponding maxima in the transient absorption spectra. $\mathrm{T}^{*}$ extracted from the ambient aerosols had strong absorption in the wavelengths of 460, 480, and 500 nm, which were employed and averaged for kinetic measurements. Typically, signals from 30 repeated pulses were averaged for each observation wavelength.

All experiments were conducted under pseudo first order conditions due to a large excess of the quencher (i.e., S(IV)) compared to the initial photosensitizer concentrations. The absorption decay traces of the photosensitizer triplet state were fitted well with a single exponential process: 


$$
\mathrm{y}=\mathrm{a}+\mathrm{b} e^{-k_{1} t}
$$

where $\mathrm{k}_{1}\left(\mathrm{~s}^{-1}\right)$ is the pseudo first order rate constant obtained from the slope of a logarithmic plot of the transient signals, and "a” reflects potential deviation of the base line after excitation (i.e., when the absorption does not return to zero when absorbing products are produced). The lifetime of $\mathrm{T}^{*}$ was defined as:

$$
\tau=\frac{1}{k_{1}}
$$

In the bulk aqueous experiments in this study, in order to investigate the reactivity of hydrated $\mathrm{SO}_{2}$ and $\mathrm{HSO}_{3}{ }^{-}$with $\mathrm{T}^{*}$, sodium sulfite was added into the photosensitizer solutions, then $\mathrm{pH}$ of the solutions was decreased to 1.8 or 2.6 by adding a $\mathrm{H}_{2} \mathrm{SO}_{4}$ solution. Under these conditions, S(IV) existed mainly as hydrated $\mathrm{SO}_{2}$ and $\mathrm{HSO}_{3}{ }^{-}$. The quenching rate coefficients for $\mathrm{T}^{*}$ in the presence of S(IV) were determined by the Stern-Volmer equation (Eq. 6):

$$
\begin{aligned}
-\frac{d\left[T^{*}\right]}{d t} & =\left(k_{0}+k_{q\left(\mathrm{SO}_{2} \cdot \mathrm{H}_{2} \mathrm{O}\right)}\left[\mathrm{SO}_{2} \cdot \mathrm{H}_{2} \mathrm{O}\right]+k_{q\left(\mathrm{HSO}_{3}^{-}\right)}\left[\mathrm{HSO}_{3}^{-}\right]\right)\left[\mathrm{T}^{*}\right] \\
& =k_{o b s}\left[\mathrm{~T}^{*}\right]
\end{aligned}
$$

where $\mathrm{k}_{0}$ corresponds to the rate coefficient of $\mathrm{T}^{*}$ decay in the absence of oxygen or other quenchers, and $k_{q\left(\mathrm{SO}_{2} \cdot \mathrm{H}_{2} \mathrm{O}\right)}$ and $k_{q\left(\mathrm{HSO}_{3}^{-}\right)}$are the rate coefficients for the quenching by hydrated $\mathrm{SO}_{2}$ and $\mathrm{HSO}_{3}{ }^{-}$, respectively. It is important to underline that these rate constants are dependent on temperature but also $\mathrm{pH}$.

\section{Results}

Figure 1A shows the effect of such chemistry at 295-300 K, the diluted $\mathrm{SO}_{2}$ gas flowing through a $14 \mathrm{~mL}$ reactor filled halfway with aqueous solutions containing different photosensitizers, and illuminated with light simulating actinic irradiation $(\lambda>290 \mathrm{~nm})$. Various types of atmospherically relevant photosensitizing chemicals were used, namely 4- (benzoyl)benzoic acid (4-BBA), humic 
acids and their salts (HA and HAS), and finally extracts from filter samples collected in a rural area $\left(38^{\circ} 42^{\prime} \mathrm{N}, 115^{\circ} 08^{\prime} \mathrm{E}\right)$ close to Beijing during haze events in winter 2018 (AA1 and AA2, which differ by their $\mathrm{pH} ; \mathrm{pH}=4.6$, acidified with $\mathrm{H}_{2} \mathrm{SO}_{4}$, and 6.2, respectively). These filters were shown, by UPLC/DAD/(+/-)HESI-HRMS, to be chemically complex, with more than seventy carbonyl-containing compounds and a large amount of light-absorbing chromophoric compounds (Fig. S2 and Database S1).

These solutions were initially exposed to a gaseous flow of $\mathrm{SO}_{2}$ until steady $\mathrm{SO}_{2}$ concentrations were reached at the outlet of the reactor, with gas phase concentrations in the range from 40-100 ppbv. During these conditioning periods, Henry’s law equilibrium and acid-base dissociation were taking place, leading to the production of hydrated $\mathrm{SO}_{2}, \mathrm{HSO}_{3}{ }^{-}$and eventually $\mathrm{SO}_{3}{ }^{2-}$ The product distribution is highly $\mathrm{pH}$ dependent, with $\mathrm{SO}_{2}$ being prevalent at $\mathrm{pH}<2$, $\mathrm{HSO}_{3}{ }^{-}$between 3 and 6 , and finally $\mathrm{SO}_{3}{ }^{2-}$ above $\mathrm{pH}=7^{18}$ (see $\mathrm{pKa}$ values in Eqs. 2-3).

Once the outlet gaseous $\mathrm{SO}_{2}$ concentration was stabilized (with the exception of AA2 due to its higher $\mathrm{pH}$ ), the light was switched on, and for all samples, we observed a sudden loss of gas phase $\mathrm{SO}_{2}$ associated with synchronous sulfate production in the liquid phase (see Fig. 1B). Such a loss is a clear indication that light initiated the conversion of hydrated $\mathrm{SO}_{2}$ or $\mathrm{HSO}_{3}{ }^{-}$to $\mathrm{SO}_{4}{ }^{2-}$, and hence the oxidation proceeds from S(IV) to S(VI).

$\mathrm{SO}_{2}$ consumption was not observed in the absence of the photosensitizing compounds i.e., no loss on irradiated pure water. This result, combined with the poor light absorption of $\mathrm{SO}_{2}$ in the wavelength region $(\lambda>295 \mathrm{~nm})$ considered here, shows that in this case the triplet state reaction of $\mathrm{SO}_{2}$ with water plays a minor role. We attributed the loss of gaseous $\mathrm{SO}_{2}$ to a chemical reaction between dissolved S(IV) and the photosensitizer triplet state or oxidants produced from the excited state and oxygen. In fact, it has been shown that both humic acids, and 4-BBA are sources of $\mathrm{HO}_{2}$ 
204 (and hence $\mathrm{OH}$ ) radicals when exposed to light ${ }^{13,19}$. The formation of such radicals could then 205 readily react with dissolved S(IV) and lead to the observations depicted in Fig. 1. Interestingly, 206 similar trends were observed when the carrier gas was changed to pure nitrogen and all solutions 207 deoxygenated. This clearly rules out the influence of secondary oxidants, produced in the solution, 208 but point towards a direct reaction of S(IV) and the excited state of the photosensitizer.

209 To test whether such a sulfate production could also be observed under different conditions, we 210 performed aerosol flow tube experiments. Here, a bulk solution containing 4-BBA was nebulized 211 producing aerosols, then aerosols were dried, size selected (70 or $80 \mathrm{~nm}$ ), and injected into the 212 flow tube with a residence time of ca. 15 min. $\mathrm{SO}_{2}$ was injected at around $630 \mathrm{ppb}$ in pure air 213 acting as carrier gas. At the reactor outlet, particles were chemically characterized by means of an 214 Aerosol Mass Spectrometer (AMS, Aerodyne), which is highly sensitive to sulfate. This is a 215 similar approach to the one previously used for investigating photosensitized organic aerosol 216 growth ${ }^{20}$. As shown by Fig. 1C, once the lights were switched on, we observed a clear production 217 of sulfate in the particle phase, similarly to the bulk experiments above (note that due to the low 218 surface-to-volume ratio, the loss of gaseous $\mathrm{SO}_{2}$ could not be monitored in these experiments). In 219 other words, we observed a photosensitized sulfate production, which took place within the $220 \quad$ condensed phase.

221 Triplet excited states are often considered as more significant excited states in photochemistry 222 comparing to the singlet excited states, due to their longer lifetimes. Laser-flash illumination of 223 some selected photosensitizers, which are simultaneously representative of those found in 224 dissolved organic matter and biomass burning plumes (including fires for residential heating) ${ }^{13}$, in 225 deoxygenated aqueous solutions led to the production of the corresponding triplet state, whose 226 decay was monitored as a function of time ${ }^{21}$ to derive the corresponding rate constant as a function 
of reactant concentration, $\mathrm{pH}$, etc. (as detailed below). Firstly, the quenching rates of these triplet states were observed to be highly pH dependent in absence of added S(IV), with acetophenone and 4-BBA being quenched faster under more acidic conditions, but with no obvious influences on flavone and xanthone in this $\mathrm{pH}$ range (Fig. 2A and Fig. S3). In addition to highlighting their $\mathrm{pH}$ dependence, those trends are useful to discriminate which S(IV) species in reactive with a given T*.

Figure S4 shows experiments being performed by adding sodium sulfite $\left(\mathrm{Na}_{2} \mathrm{SO}_{3}\right)$ into the deoxygenated aqueous solutions, which redistributed into the other S(IV) compounds depending on $\mathrm{pH}$ (their distribution in solution can be calculated based on the equilibrium Eqs. 1-3). It appeared that all investigated triplet states were efficiently quenched by the presence of aqueous S(IV) species but exhibited different quenching rates (see Fig. 2B and Fig. 3). Fig. 2B shows the quenching rates of the triplet states in the presence of the same concentration of S(IV) but at different pH i.e., with a different speciation between hydrated $\mathrm{SO}_{2}$ and $\mathrm{HSO}_{3}{ }^{-}$. Taking into account the trends shown in Fig 2A, these results indicate that the triplet state of flavone is more reactive toward hydrated $\mathrm{SO}_{2}$, while xanthone is more reactive toward $\mathrm{HSO}_{3}{ }^{-}$(see Table $\mathrm{S} 1$ ). However, the triplet states of acetophenone and 4-BBA were quenched faster under more acidic solutions, as they are more reactive under acidic conditions (see Fig. 2A) and also probably more reactive toward hydrated $\mathrm{SO}_{2}$.

In the investigated $\mathrm{pH}$ range, both hydrated $\mathrm{SO}_{2}$ and $\mathrm{HSO}_{3}{ }^{-}$were quenching or reacting with $\mathrm{T}^{*}$. Figure 3 shows a Stern-Volmer plot of the measured quenching rates under acidic conditions where hydrated $\mathrm{SO}_{2}$ and $\mathrm{HSO}_{3}{ }^{-}$are in the dominant. In order to simplify the kinetics treatment, we assumed that both S(IV) species are reacting at the same rate with the triplet state. In such a simplified system, the observed quenching rate should depend linearly with the total aqueous S(IV) 
concentration (see Fig. 3). The measured second order rate constants were all in excess of $6 \times 10^{7}$ $\mathrm{M}^{-1} \mathrm{~S}^{-1}$, with 4-BBA being the slowest $\left(6.9 \times 10^{7} \mathrm{M}^{-1} \mathrm{~s}^{-1}\right)$ and xanthone the fastest $\left(1.0 \times 10^{9} \mathrm{M}^{-1} \mathrm{~s}^{-1}\right)$. The extracts of the ambient filters from an authentic Chinese haze event also showed a reactive triplet state, and quenched by S(IV) with a rate constant of $1.3 \times 10^{8} \mathrm{M}^{-1} \mathrm{~s}^{-1}$ (see Fig. 3).

\section{Discussion}

These observations can only be explained by a direct reaction between S(IV) species and the studied triplet states ( $\left.\mathrm{T}^{*}\right)$, as the organic photodissociation is not occurring under our experimental conditions with well defined photosensitizers. The possible reaction pathways are listed below:

$$
\begin{aligned}
& \rightarrow \quad \mathrm{SO}_{2} *+\mathrm{T} \text {; energy transfer (a) } \\
& \mathrm{SO}_{2}(\mathrm{aq})+\mathrm{T}^{*} \quad \rightarrow \quad \mathrm{SO}_{2}{ }^{++}+\mathrm{T}^{*} \text {; electron transfer to } \mathrm{T}^{*}(\mathrm{~b}) \\
& \rightarrow \quad \mathrm{SO}_{2}{ }^{-{ }^{-}+\mathrm{T}^{++}} \text {; electron transfer from } \mathrm{T}^{*} \text { (c) } \\
& \mathrm{HSO}_{3}{ }^{-}+\mathrm{T}^{*} \quad \rightarrow \quad \mathrm{HSO}_{3}{ }^{-}+\mathrm{T}^{*} \text {; electron transfer to } \mathrm{T}^{*}(\mathrm{~d}) \\
& \rightarrow \quad \mathrm{SO}_{3}{ }^{--}+\mathrm{HT} \text {; hydrogen transfer to } \mathrm{T}^{*}(\mathrm{e})
\end{aligned}
$$

All these initiation reactions are producing a sulfur containing transient compounds that will start chain reactions and decay to sulfate. While we cannot, from our observations, be fully conclusive on the exact reaction mechanism, one could still discuss the plausibility of each pathway. Let us consider, 4-BBA as a model photosensitizer for which some information is known (in contrast for instance to the authentic aerosol samples). The energy of the triplet of 4-BBA ( 290 $\left.\mathrm{kJ} \mathrm{mol}^{-1}\right)^{13}$ is slightly lower than the triplet energy of $\mathrm{SO}_{2}\left(\sim 300 \mathrm{~kJ} \mathrm{~mol}^{-1}\right)^{7}$, which cannot lead to an efficient (if any) energy transfer in this case. However, one cannot rule out that for higher triplet states, energy transfer could lead to a significant yield of excited state $\mathrm{SO}_{2}$ (pathway (a)) that would then react more efficiently with water, producing $\mathrm{OH}$ radicals and therefore led to the observed 
oxidation process ${ }^{9}$. An electron transfer, either way, would therefore be the prominent pathway.

$\mathrm{SO}_{2}$ has a zwitterion structure, where the sulfur is positively charged, which would prevent any significant electron transfer from its electron lone-pairs. However, if produced through pathway (b), $\mathrm{SO}_{2}{ }^{+}$might react directly with water and initiate some further radical and oxidative chemistry ${ }^{22}$. Another possibility is an electron transfer to $\mathrm{SO}_{2}$ producing $\mathrm{SO}_{2}{ }^{-}$. It was however not possible to observe the transient spectra of $\mathrm{SO}_{2}{ }^{-}$, nor of the associated ketyl radical produced in pathway (c), as the absorption of the radical anion was underlying the one of the organic photosensitizer. $\mathrm{SO}_{2}{ }^{--}$has been previously reported to be highly reactive in aqueous solutions, undergoing several reaction pathways including reactions with oxygen and typical S(IV) species, ending in the production of sulfate ${ }^{23-25}$. In addition, $\mathrm{HSO}_{3}{ }^{-}$could also either transfer the electron to $\mathrm{T}^{*}$ producing $\mathrm{HSO}_{3}{ }^{\circ}$ (d) or a $\mathrm{H}$-atom producing $\mathrm{SO}_{3}{ }^{-}$(e), which could also continue to react with oxygen and other S(IV) species to produce sulfate ${ }^{23}$. This reaction scheme would probably explain the measured quenching rates.

While the exact pathway is uncertain, the reaction rates are however established via the kinetics observations discussed above. If we assume, that the reaction between $\mathrm{S}(\mathrm{IV})$ and $\mathrm{T}^{*}$ is the rate limiting step and rate coefficient is $\mathrm{pH}$ independent, then one can derive the associated sulfate formation rates. The $\mathrm{pH}$ independence is arising from the assumption made that both hydrated $\mathrm{SO}_{2}$ and $\mathrm{HSO}_{3}{ }^{-}$have similar reactivities and that the total aqueous $\mathrm{S}(\mathrm{IV})$ concentration can be used as a reasonable proxy, leading to the linearity shown in Fig. 3. Details about these calculations are given in the Supporting Information. It also should be noted that here particles were assumed to be homogenously mixed and in a liquid state. This chemistry (Reactions (a-e)) may then induce a significant $\mathrm{S}(\mathrm{IV})$ oxidation in wet aerosols, when both $\mathrm{SO}_{2}$ and particle phase photosensitizers, such as HULIS ${ }^{14}$, levels are high. Such conditions are typically observed during Asian haze events, 
which combine high humidity and significant anthropogenic emissions from residential burning, with a contribution of up to 20 wt. \% during haze events. By updating the scenario of Cheng et al. ${ }^{10}$ to take into account high $\mathrm{H}_{2} \mathrm{O}_{2}$ levels recently reported ${ }^{26}$, we estimated the sulfate formation rate associated with $\mathrm{SO}_{2}$ reacting with $\mathrm{O}_{3}, \mathrm{H}_{2} \mathrm{O}_{2}$, TMIs, $\mathrm{NO}_{2}$ and $\mathrm{T}^{*}$ (using $1.3 \times 10^{8} \mathrm{M}^{-1} \mathrm{~s}^{-1}$ as obtained from the authentic samples) (Fig. 3). It should be noted again that we assumed that the triplet states are reactive toward all S(IV) species (hydrated $\mathrm{SO}_{2}$ and $\mathrm{HSO}_{3}{ }^{-}$) and independent of their actual pH speciation (Eqs. 1-3). To estimate the sulfate formation rate under the scenario set by Cheng et al. ${ }^{10}$, we do need to estimate the particle phase concentration of triplet states under steady-state haze daylight conditions. Clearly, the data related to this quantity are very limited. For instance, Kaur et al. ${ }^{27}$ reported very recently on such concentrations for some cleaner conditions encountered in California, but with large uncertainty. While, several studies investigated the amount of singlet oxygen and its ratio to coexisting triplet states in the range approximately $1^{10}$, $3^{28}$, and $10-100^{27}$, respectively. Altogether, this leads to estimated concentrations in the range from $2.3 \times 10^{-13}$ to $1.6 \times 10^{-10} \mathrm{M}^{27}$. Using this range of concentrations, leads to the estimated sulfate production rates shown in Fig. 4. Overall, these results show that the photosensitizing pathway could make a significant contribution to the sulfate formation (Fig. 4). In the pH range from 4 to 6 , which exactly under the conditions of Chinese haze ${ }^{29,30}$, the sulfate production rates are in the range of $1.1 \times 10^{-4}-7.9 \mu \mathrm{g} \mathrm{m}^{-3} \mathrm{~h}^{-1}$. This is a new finding that not only will help close gaps between field observations and numerical models, but also may help in defining new regulations to reduce sulfate formation, and hence the harmful effects of these haze events. Overall, this study also stresses the knowledge gap around particle phase concentration of photosensitizing compounds and the associated quantum yield for triplet state formation. 


\section{Acknowledgments}

Funding: This project was supported by the ANR-RGC programme (project ANR-16-CE01-0013, A-PolyU502/16), the European Union’s Horizon 2020 research and innovation program under grant agreement No. 690958 (MARSU), the Ministry of Science and Technology of China (2016YFC0202700), the National Natural Science Foundation of China (91843301, 91743202), and the National research program for key issues in air pollution control (DQGG0103, DQGG0102). SN thanks the Université Claude Bernard Lyon 1 for providing him with a visiting professorship at in the summer of 2018. CG thanks Kristopher McNeil for very helpful discussions and comments on the reaction mechanism. Competing interests: The authors declare no competing interests. Data and materials availability: All data to support the conclusions of this manuscript are included in the main text and Supporting Information. Supporting Information: Additional experimental details, 4 figures, 3 tables and dataset S1 were given.

\section{References and Notes:}

1. Albrecht, B. A., Aerosols, Cloud Microphysics, and Fractional Cloudiness. Science 1989, 245, (4923), 1227-1230.

2. Sedlak, D. L.; Hoigne, J., Oxidation of S(IV) in Atmospheric Water by Photooxidants and Iron in the Presence of Copper. Environmental Science \& Technology 1994, 28, (11), 1898-1906.

3. $\quad$ Warneck, P., Chemistry of the Natural Atmosphere. Academic Press: 2000.

4. $\quad$ Guo, S.; Hu, M.; Zamora, M. L.; Peng, J.; Shang, D.; Zheng, J.; Du, Z.; Wu, Z.; Shao, M.; Zeng, L.; Molina, M. J.; Zhang, R., Elucidating severe urban haze formation in China. Proc. Natl. Acd. Sci. 2014, 111, (49), 17373-17378.

5. $\quad$ Wang, Y.; Zhang, Q.; Jiang, J.; Zhou, W.; Wang, B.; He, K.; Duan, F.; Zhang, Q.; Philip, S.; Xie, Y., Enhanced sulfate formation during China's severe winter haze episode in January 2013 missing from current models. J Geophys. Res. - Atm. 2014, 119, (17), 10,425-10,440.

6. Hung, H.-M.; Hoffmann, M. R., Oxidation of Gas-Phase $\mathrm{SO}_{2}$ on the Surfaces of Acidic Microdroplets: Implications for Sulfate and Sulfate Radical Anion Formation in the Atmospheric Liquid Phase. Environ. Sci. Tech. 2015, 49, (23), 13768-13776.

7. Donaldson, D. J.; Kroll, J. A.; Vaida, V., Gas-phase hydrolysis of triplet $\mathrm{SO}_{2}$ : A possible direct route to atmospheric acid formation. Scientific Reports 2016, 6, 30000.

$8 . \quad$ Kroll, J. A.; Frandsen, B. N.; Kjaergaard, H. G.; Vaida, V., Atmospheric Hydroxyl Radical Source: Reaction of Triplet $\mathrm{SO}_{2}$ and Water. The Journal of Physical Chemistry A 2018, 122, (18), 4465-4469.

9. Martins-Costa, M. T. C.; Anglada, J. M.; Francisco, J. S.; Ruiz-López, M. F., Photochemistry of $\mathrm{SO}_{2}$ at the Air-Water Interface: A Source of OH and HOSO Radicals. J. Am. Chem. Soc. 2018, 140, (39), 12341-12344. 
10. Cheng, Y.; Zheng, G.; Wei, C.; Mu, Q.; Zheng, B.; Wang, Z.; Gao, M.; Zhang, Q.; He, K.; Carmichael, G.; Pöschl, U.; Su, H., Reactive nitrogen chemistry in aerosol water as a source of sulfate during haze events in China. Science Advances 2016, 2, (12), e1601530.

11. Li, L.; Hoffmann, M. R.; Colussi, A. J., Role of Nitrogen Dioxide in the Production of Sulfate during Chinese Haze-Aerosol Episodes. Environ. Sci. Tech. 2018, 52, (5), 2686-2693.

12. George, C.; Ammann, M.; D’Anna, B.; Donaldson, D. J.; Nizkorodov, S. A., Heterogeneous Photochemistry in the Atmosphere. Chem. Rev. 2015, 115, (10), 4218-4258.

13. McNeill, K.; Canonica, S., Triplet state dissolved organic matter in aquatic photochemistry: reaction mechanisms, substrate scope, and photophysical properties. Environmental Science: Processes \& Impacts 2016, 18, (11), 1381-1399.

14. Baduel, C.; Monge, M. E.; Voisin, D.; Jaffrezo, J. L.; George, C.; El Haddad, I.; Marchand, N.; D’Anna, B., Environ. Sci. Technol. 2011, 45, 5238.

15. Ciuraru, R.; Fine, L.; van Pinxteren, M.; D’Anna, B.; Herrmann, H.; George, C., Photosensitized production of functionalized and unsaturated organic compounds at the air-sea interface. Scientific Reports 2015, 5, 12741.

16. Dupart, Y.; King, S. M.; Nekat, B.; Nowak, A.; Wiedensohler, A.; Herrmann, H.; David, G.; Thomas, B.; Miffre, A.; Rairoux, P.; D’Anna, B.; George, C., Mineral dust photochemistry induces nucleation events in the presence of $\mathrm{SO}_{2}$. Proc. Natl. Acd. Sci. 2012, 109, (51), 20842-20847.

17. Jammoul, A.; Dumas, S.; D'Anna, B.; George, C., Photoinduced oxidation of sea salt halides by aromatic ketones: a source of halogenated radicals. Atmos. Chem. Phys. 2009, 9, (13), 4229-4237.

18. Seinfeld, J. H.; Pandis, S. N., Atmospheric Chemistry and Physics: From Air Pollution to Climate Change. Wiley: 2006.

19. $\quad$ Canonica, S.; Jans, U.; Stemmler, K.; Hoigne, J., Environ. Sci. Technol. 1995, 29, 1822.

20. Monge, M. E.; Rosenørn, T.; Favez, O.; Müller, M.; Adler, G.; Abo Riziq, A.; Rudich, Y.; Herrmann, H.; George, C.; D’Anna, B., Alternative pathway for atmospheric particles growth. Proc. Natl. Acd. Sci. 2012, 109, (18), 6840-6844.

21. Tinel, L.; Rossignol, S.; Ciuraru, R.; Dumas, S.; George, C., Photosensitized reactions initiated by 6carboxypterin: singlet and triplet reactivity. Physical Chemistry Chemical Physics 2016, 18, (25), 17105-17115. 22. Cartoni, A.; Catone, D.; Bolognesi, P.; Satta, M.; Markus, P.; Avaldi, L., $\mathrm{HSO}_{2}{ }^{+}$Formation from IonMolecule Reactions of $\mathrm{SO}_{2}{ }^{+}$with Water and Methane: Two Fast Reactions with Reverse Temperature-Dependent Kinetic Trend. Chemistry - A European Journal 2017, 23, (28), 6772-6780.

23. Neta, P.; Huie, R. E.; Harriman, A., One-electron-transfer reactions of the couple $\mathrm{SO}_{2} / \mathrm{SO}_{2}{ }^{-}$in aqueoussolutions - pulse radiolytic and cyclic voltammetric studies. J. Phys. Chem. 1987, 91, (6), 1606-1611.

24. Burlamacchi, L.; Guarini, G.; Tiezzi, E., Mechanism of decomposition of sodium dithionite in aqueous solution. Trans. Faraday Soc. 1969, 65, (554P), 496-502.

25. Rinker, R. G.; Gordon, T. P.; Mason, D. M.; Sakaida, R. R.; Corcoran, W. H., Kinetics and mechanism of the air oxidation of the dithionite ion $\left(\mathrm{S}_{2} \mathrm{O}_{4}{ }^{3}\right)$ in aqueous solution. J. Phys. Chem. 1960, 64, (5), 573-581.

26. Ye, C.; Liu, P.; Ma, Z.; Xue, C.; Zhang, C.; Zhang, Y.; Liu, J.; Liu, C.; Sun, X.; Mu, Y., High $\mathrm{H}_{2} \mathrm{O}_{2}$ Concentrations Observed during Haze Periods during the Winter in Beijing: Importance of $\mathrm{H}_{2} \mathrm{O}_{2}$ Oxidation in Sulfate Formation. Environ. Sci. Technol. 2018, 5, (12), 757-763.

27. Kaur, R.; Labins, J. R.; Helbock, S. S.; Jiang, W.; Bein, K. J.; Zhang, Q.; Anastasio, C. Photooxidants from Brown Carbon and Other Chromophores in Illuminated Particle Extracts. Atmos. Chem. Phys. 2019, 19 (9), 65796594.

28. Kaur, R.; Anastasio, C., First Measurements of Organic Triplet Excited States in Atmospheric Waters. Environ. Sci. Tech. 2018, 52, (9), 5218-5226.

29. Song, S.; Gao, M.; Xu, W.; Shao, J.; Shi, G.; Wang, S.; Wang, Y.; Sun, Y.; McElroy, M. B., Fine-particle $\mathrm{pH}$ for Beijing winter haze as inferred from different thermodynamic equilibrium models. Atmos. Chem. Phys. 2018, 18, (10), 7423-7438.

30. Ding, J.; Zhao, P.; Su, J.; Dong, Q.; Du, X., Aerosol pH and its influencing factors in Beijing. Atmos. Chem. Phys. Discuss. 2018, 2018, 1-34. 
406

407

408

\section{Figures}

\section{Abstract Art}
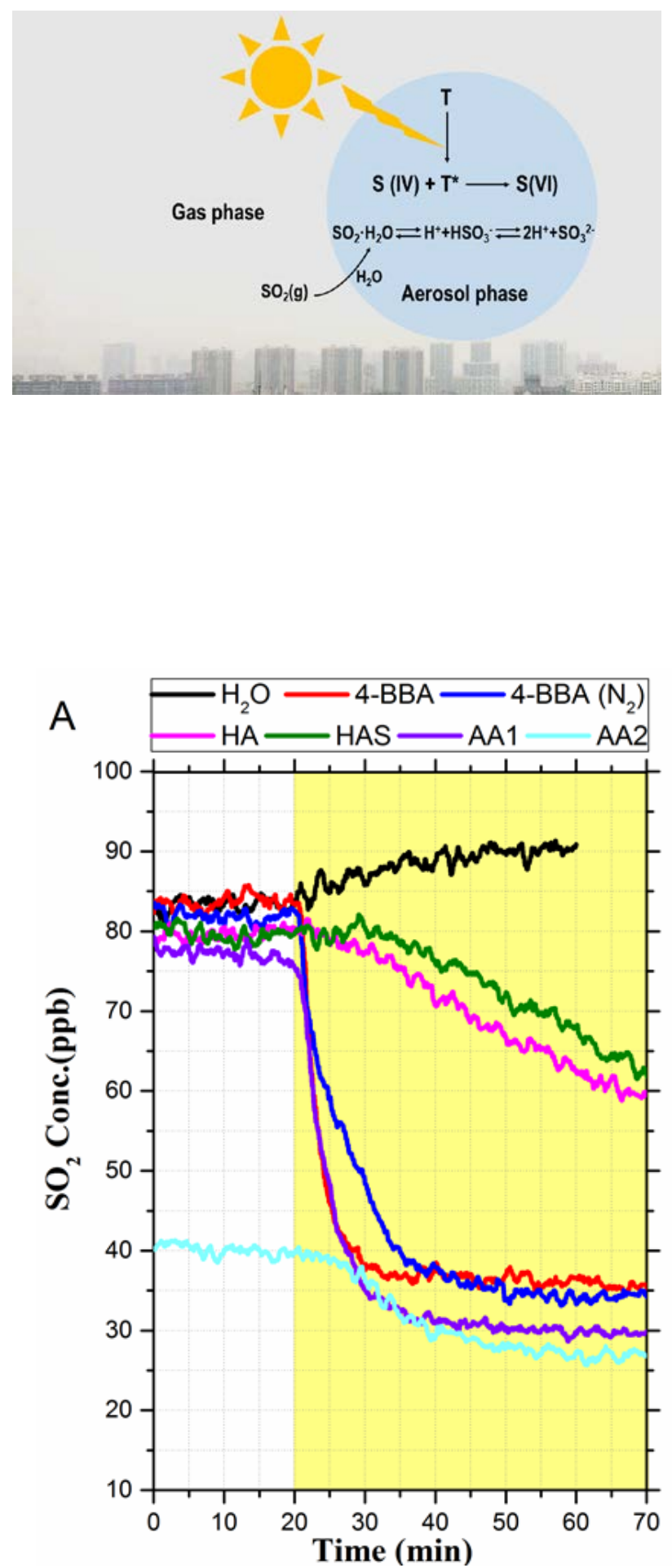


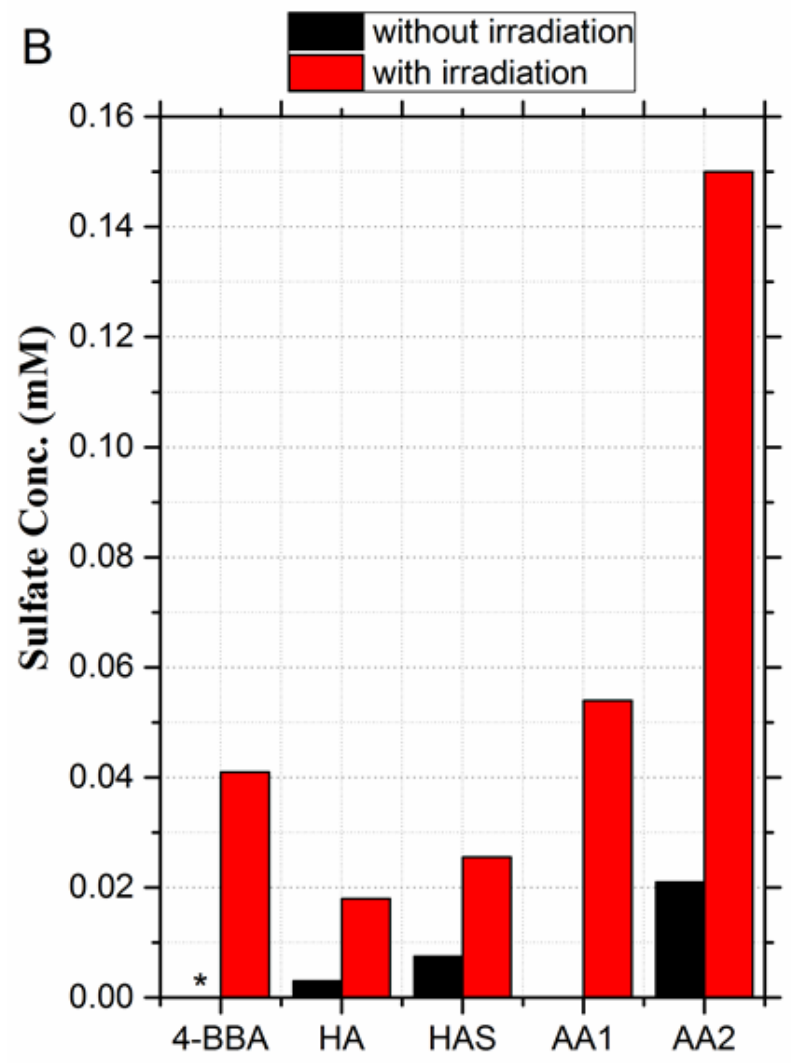

414

415

416 


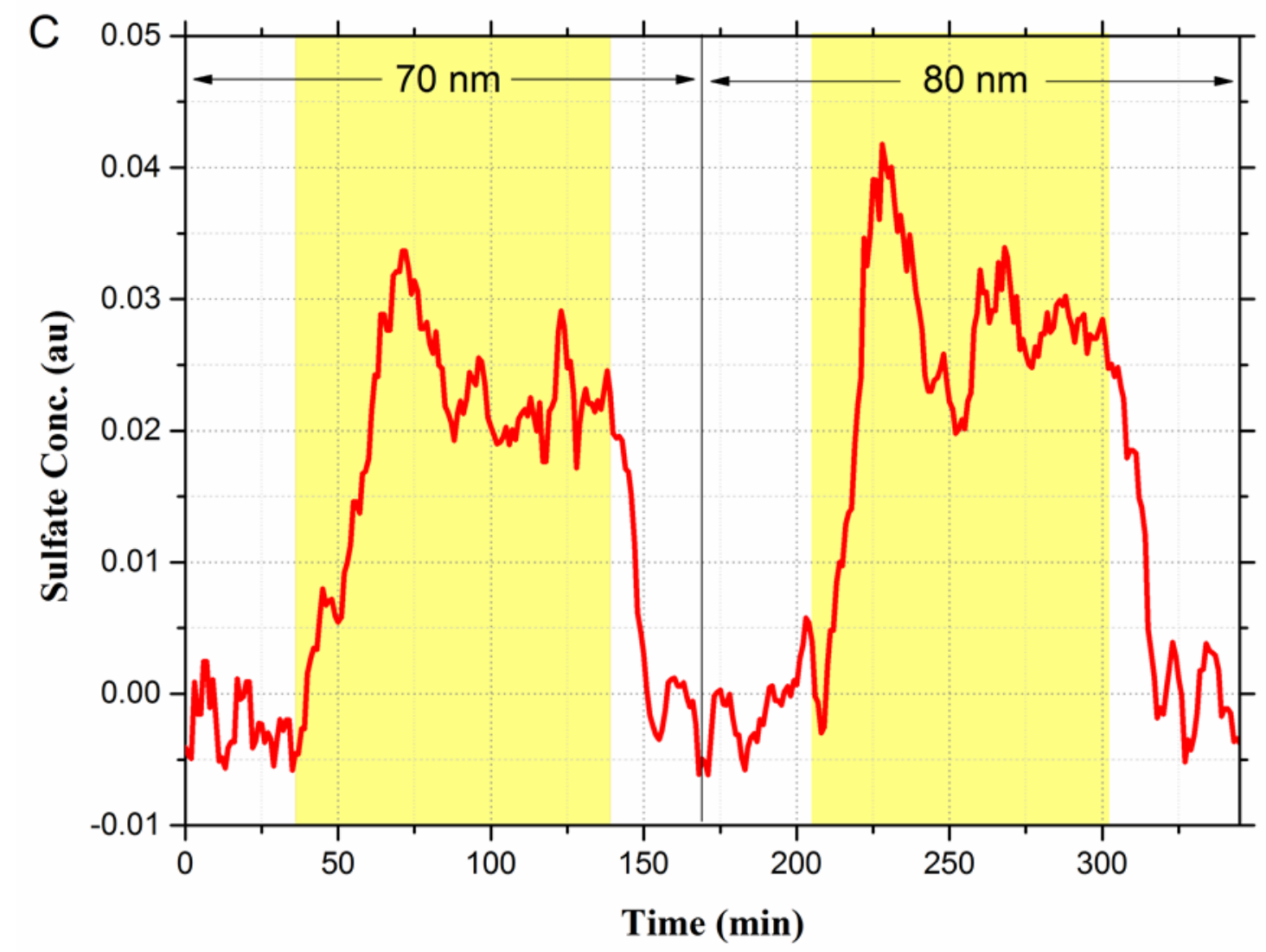

Fig. 1. $\mathrm{SO}_{2}$ loss and sulfate formation. (A) Time traces of gaseous $\mathrm{SO}_{2}$ loss above aqueous solutions of 4-BBA, HA, HAS AA1, and AA2. (B) Corresponding sulfate production. AA1 and AA2 differ by their $\mathrm{pH}$ and hence their capacity to store S(IV). Sulfate concentrations were blankcorrected for the HA, HAS, AA1 and AA2 experiments. * The concentration was below detection limit. (C) Sulfate production measured by an aerosol mass spectrometer in 4-BBA particles with diameters of 70 and $80 \mathrm{~nm}$ in the aerosol flow tube. Residence time is $15 \mathrm{~min}$. 


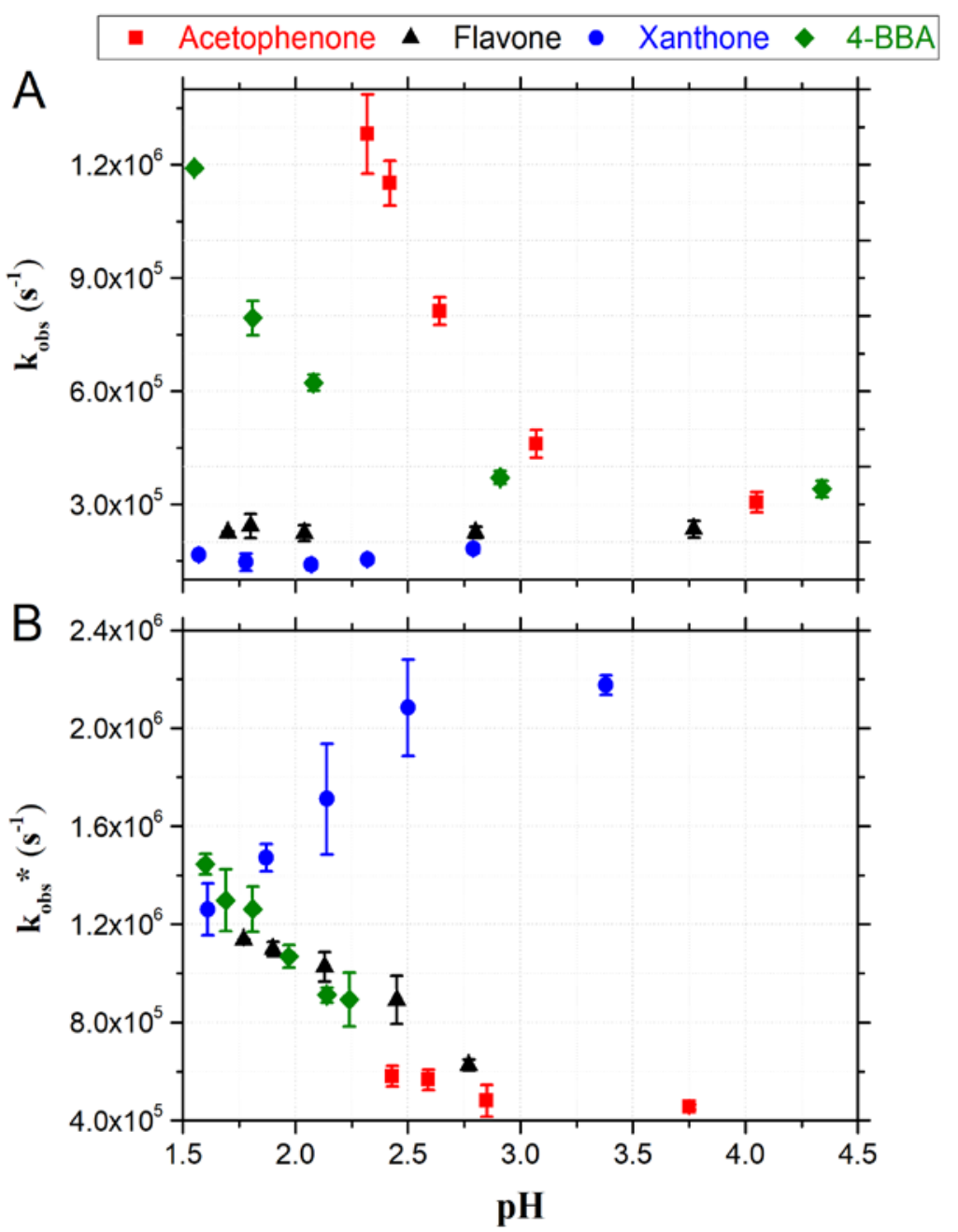

Fig. 2. The pH influence on the quenching rates of the triplet states in the absence (A) and presence (B) of S(IV). Red squares, acetophenone, $0.25 \mathrm{mM}$ sodium sulfite; black triangles, flavone, $0.1 \mathrm{mM}$ sodium sulfite; blue circles, xanthone, $1 \mathrm{mM}$ sodium sulfite; green diamonds, 4BBA, $20 \mathrm{mM}$ sodium sulfite. $\mathrm{k}_{\mathrm{obs}}$ * is the blank-corrected quenching rates, which means here these values obtained from the triplet states being quenched only by S(IV). It should be noted that here xanthone concentrations were different from other xanthone experiments in this study. 


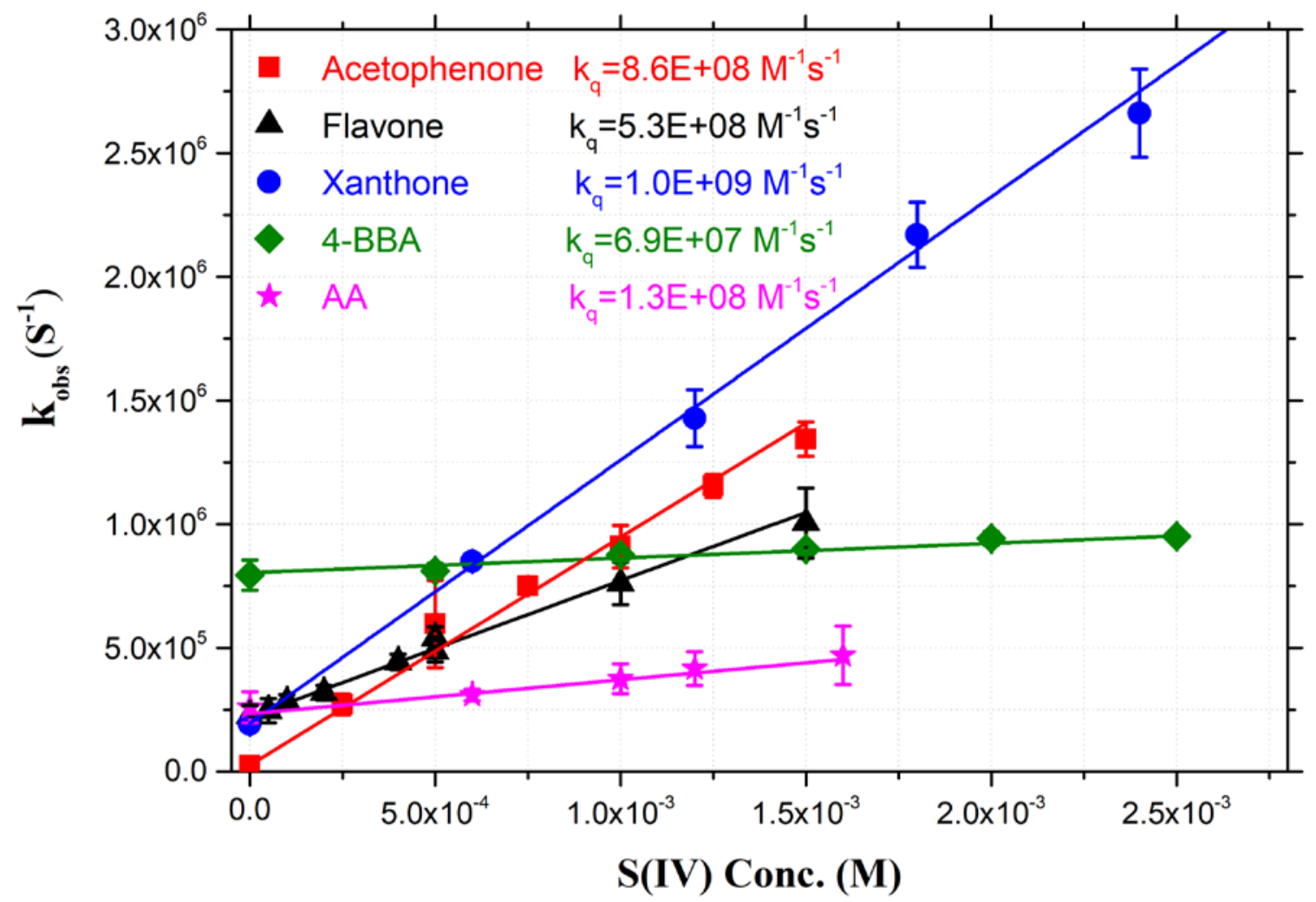

Fig. 3. Stern-Volmer plots of the observed quenching first-order rate coefficients kobs as a function of aqueous S(IV) concentration. Red squares, acetophenone; black triangles, flavone; blue circles, xanthone; green diamonds, 4-BBA; pink stars, HULIS-AA. The pH of all acetophenone solutions is 2.6 and the $\mathrm{pH}$ of all flavone, xanthone, 4-BBA, and HULIS-AA solutions is 1.8 . 


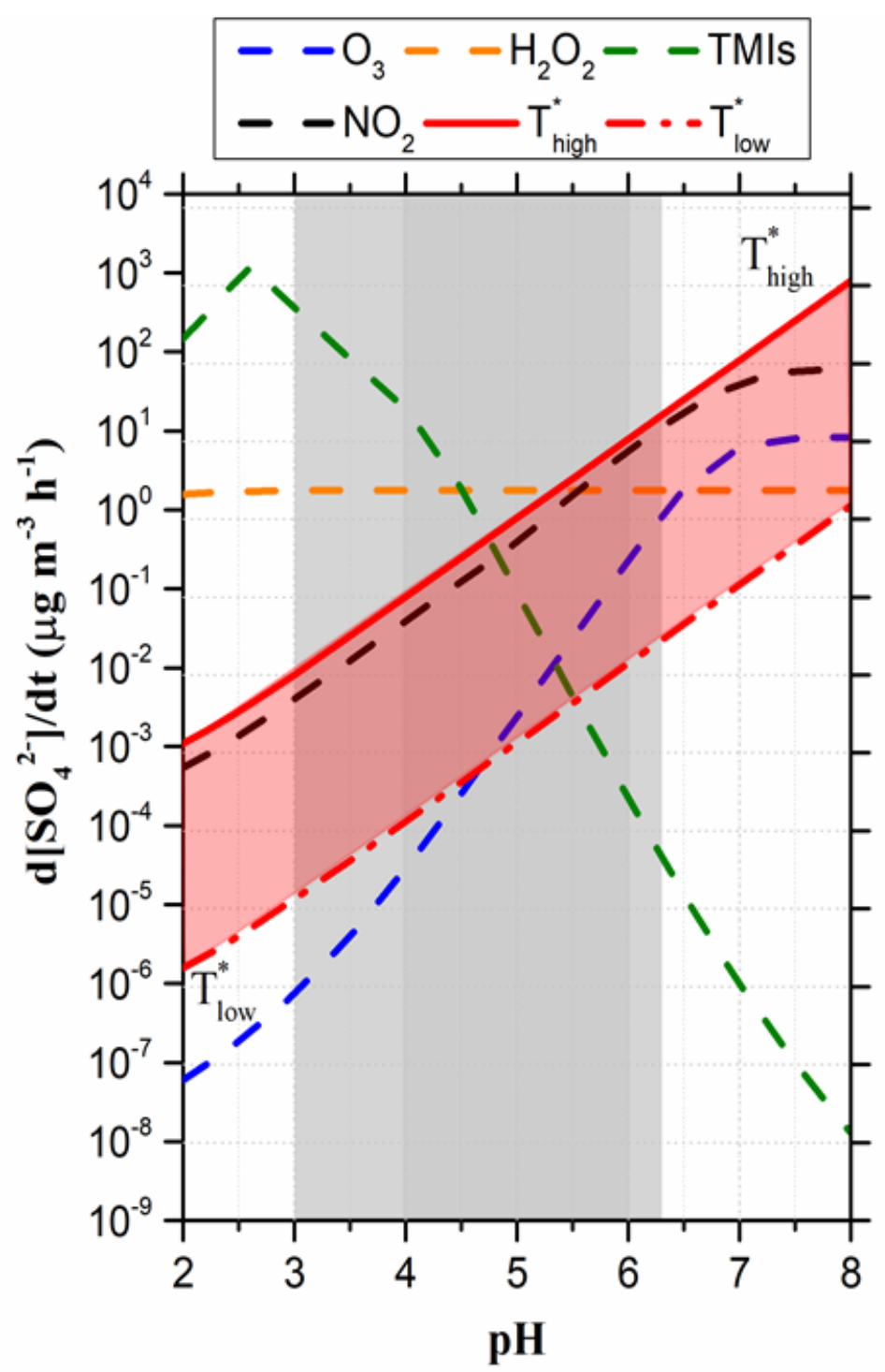

Fig. 4. Sulfate production rates for Beijing winter haze calculated for main aqueous-phase reaction pathways versus $\mathbf{p H}$. The blue, orange, green, and black lines represent $\mathrm{O}_{3}, \mathrm{H}_{2} \mathrm{O}_{2}$, TMIs, and nitrogen dioxide $\left(\mathrm{NO}_{2}\right)$ pathways, respectively, from Cheng et al. ${ }^{10}$. The red region represents the photosensitized oxidation. Gray-shaded areas indicate characteristic $\mathrm{pH}$ ranges during haze episodes in China, with the darker ones being more common ${ }^{29,30}$. 